FELIPE MATTE RUSSOMANNO

Mudança de regime de bens no casamento

Dissertação de Mestrado

Orientador: Professor Associado Dr. José Fernando Simão

UNIVERSIDADE DE SÃO PAULO

FACULDADE DE DIREITO

São Paulo-SP

2019 
FELIPE MATTE RUSSOMANNO

\section{Mudança de regime de bens no casamento}

Dissertação de Mestrado, apresentada à Banca Examinadora do Programa de Pós-Graduação em Direito, da Faculdade de Direito da Universidade de São Paulo, na área de concentração em Direito Civil, sob a orientação do Professor Associado Dr. José Fernando Simão.

UNIVERSIDADE DE SÃO PAULO

FACULDADE DE DIREITO

São Paulo-SP 
Serviço de Processos Técnicos da Biblioteca da Faculdade de

Direito da Universidade de São Paulo

Russomanno, Felipe Matte

Mudança de regime de bens no casamento / Felipe Matte Russomanno. - São Paulo : F. M. Russomanno, 2019.

$218 \mathrm{f.} ; 30 \mathrm{~cm}$.

Dissertação (Mestrado) - Universidade de São Paulo, 2019.

Orientador: Prof. José Fernando Simão.

Notas de rodapé.

Inclui bibliografia.

1. Alteração do regime de bens. 2. Casamento. 3. Requisitos. 4. Eficácia ex nunc. 5. Proteção a terceiros. 6. Partilha de bens. 7. Mancomunhão. 8. Direito intertemporal. 9. Direito adquirido. 10. Ato jurídico perfeito. I. Simão, José Fernando. II. Título. 


\section{Mudança de regime de bens no casamento}

Dissertação de Mestrado, apresentada à Banca

Examinadora do Programa de Pós-Graduação em Direito, da Faculdade de Direito da Universidade de São Paulo, na área de concentração em Direito Civil, sob a orientação do Professor Associado Dr. José Fernando Simão.

São Paulo, de de 2019.

Nome:

Nome:

Nome:

Nome:

Nome: 
Aos meus pais, por tudo que sempre fizeram por mim. 


\section{AGRADECIMENTOS}

Este trabalho foi escrito a muitas mãos, e é chegada a hora de agradecer àqueles que tornaram a sua conclusão possível.

De início, agradeço ao meu orientador, Professor José Fernando Simão, exemplo de amor e dedicação à academia, pela orientação, pelos ensinamentos e pelas diversas oportunidades de engrandecimento pessoal e profissional proporcionadas.

Agradeço, também, ao escritório Tucci Advogados Associados, especialmente aos sócios José Rogério Cruz e Tucci e Cibele Pinheiro Marçal Tucci, por terem acreditado em mim ao me "importarem" do Rio Grande do Sul, pelos ensinamentos durante cinco anos de trabalho e pelo exemplo de profissionais competentes, éticos e dedicados.

Também agradeço aos meus colegas Vagner Mendes Bernardo, Heitor Sica, Rogério Lauria Marçal Tucci, Pedro Caetano Dias Lourenço, Nálian Lopes Ferreira, Roberta Marques de Moraes Tucci e Bianca Marçal Tucci, assim como aos estagiários Bruna Cordeiro Silva, Carolina Solis Villares, Lucas Martho Marcon e Maria Clara Lôbo Junqueira de Andrade, pela parceria do dia a dia, pela troca de conhecimento e por terem segurado os "rojões" enquanto precisei me dedicar à dissertação de mestrado.

Agradeço aos meus colegas de pós-graduação Bruno Marques, Maria Beatriz de Toledo e Marília Elena de Souza Caldeira, os quais dividiram comigo muito mais do que seminários e artigos, mas as angústias próprias de pós-graduandos, além de conhecimento e experiências, que me acompanharão além dos muros da São Francisco.

Agradeço à minha família do coração que construí em São Paulo, que sempre me ajudou a seguir em frente, quando achei que não fosse dar conta de tudo: Bruno Bastos Becker, Chiavelli Faccenda Falavigno, Filipe Venturini Signorelli, João Pedro Madureira, Martha Giugno Termignoni e Telma Rocha Lisowski.

Agradeço, ainda, ao Fabio Carvalho Nicoletti pelo companheirismo, pelo apoio, pela paciência e pelas palavras sábias sempre no momento certo, que contribuíram sobremaneira para que o objetivo deste trabalho fosse alcançado.

Por fim, mas não menos importante, agradeço à minha família, em especial aos meus pais e à minha avó, que, mesmo a distância, sempre estiveram ao meu lado incondicionalmente, por me ensinar valores que pautam a minha existência, por me fazer 
acreditar que os sonhos são possíveis e por entender que a minha ausência em momentos essenciais sempre teve um motivo importante. 


\section{RESUMO}

RUSSOMANNO, Felipe Matte. Mudança de regime de bens no casamento. 2019. 219 p. Dissertação (Mestrado) - Universidade de São Paulo, São Paulo.

Este trabalho visa a analisar o tratamento dado pelo Direito brasileiro à mutabilidade do regime de bens no curso do casamento, enfrentando as inúmeras polêmicas que surgiram a respeito do tema. Para tanto, em primeiro lugar, são abordadas questões fundamentais para os regimes de bens, como o próprio conceito do instituto, os princípios incidentes sobre eles e, por fim, o pacto antenupcial, instrumento por meio do qual os nubentes podem regular os aspectos patrimoniais do casamento a ser celebrado. Feito isso, passa-se à segunda parte do trabalho, em que são estudados de forma crítica os requisitos para a alteração do regime de bens no curso do casamento, alguns dos quais prescindíveis para o fim a que se pretendem. Ainda na segunda parte, analisam-se a eficácia da alteração do regime de bens e a possibilidade jurídica de se proceder à partilha de bens por ocasião da mudança de regime de bens, buscando definir a situação do patrimônio comum no período compreendido entre a alteração e a efetiva partilha. Por fim, examina-se a influência do direito intertemporal sobre a mutabilidade do regime de bens, na medida em que, com o rompimento do princípio da imutabilidade do regime de bens, vigente até a entrada em vigor do Código Civil de 2002, muitos pares casados sob a égide da legislação revogada pretenderam a alteração do estatuto patrimonial de seu matrimônio, surgindo amplo debate a respeito de o artigo 2.039 do Código Civil constituir um óbice à pretensão, discussão que torna necessário o estudo a respeito do direito adquirido e do ato jurídico perfeito.

Palavras-chave: Alteração do regime de bens. Casamento. Requisitos. Eficácia ex nunc. Proteção a terceiros. Partilha de bens. Mancomunhão. Direito intertemporal. Direito adquirido. Ato jurídico perfeito. 


\begin{abstract}
RUSSOMANNO, Felipe Matte. Changing the property regime in marriage. 2019. 219 p. Dissertation (Master) - University of São Paulo, São Paulo.

This paper analyzes the treatment given by the Brazilian Law to the mutability of the property regime over the course of the marriage, confronting the several controversies over the topic. Therefore, issues crucial to property regimes will be addressed first, such as their concept, the principles inherent in them, and ultimately, the prenuptial agreement, an instrument through which both the betrothed may regulate the property aspects of the marriage to be entered into. Once that has been done, we shall proceed to the second part of the paper, which critically studies the requirements for changing the property regime over the course of the marriage, of which some are expendable for the intended purpose. The second part also analyzes the efficacy of the change in the property regime and the legal possibility of proceeding to equitable distribution due to the change in the property regime, in an attempt to define the situation of the mutual property during the period between the change and the effective distribution. Finally, it examines the influence of intertemporal law over the mutability of the property regime, to the extent that, after the rupture of the principle of the immutability of the property regime, which was in force until the entry into force of the 2002 Civil Code, many couples married under the revoked legislation intended to change the property regime of their marriage, which gave rise to a wide-ranging discussion on the fact that article 2,039 of the Civil Code constitutes an obstacle to the intention, a discussion which requires a study on the vested right and the perfect juridical act.
\end{abstract}

Keywords: Change in the property regime. Marriage. Requirements. Efficacy ex nunc. Protection to third parties. Equitable distribution. Tenancy by the entirety. Intertemporal law. Vested right. Perfect juridical act. 


\section{SUMÁRIO}

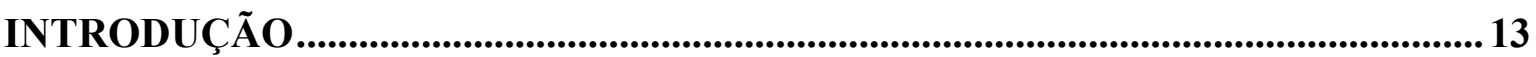

CAPÍTULO I - DISCIPLINA GERAL DOS REGIMES DE BENS............................... 17

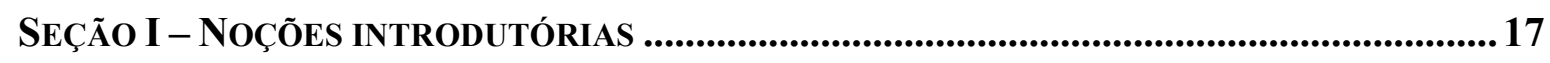

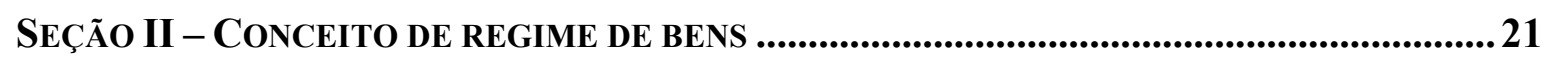

SEÇÃo III - ClaSSES DOS REGIMES DE BENS ................................................................ 24

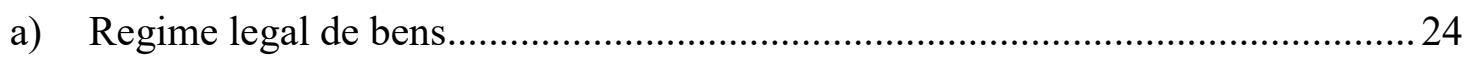

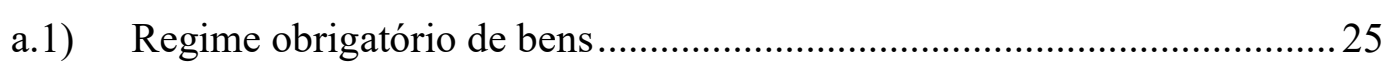

a.1.1) Da mitigação da separação obrigatória de bens ............................22

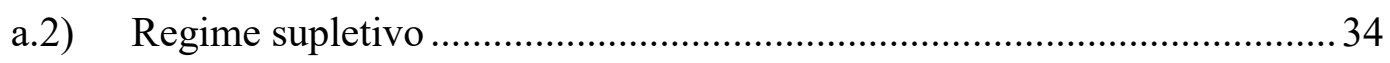

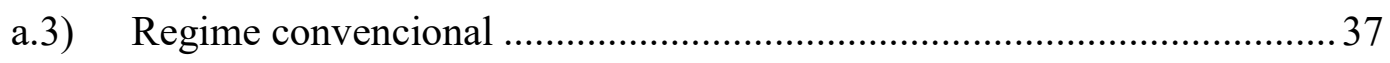

SEÇÃo IV - PRINCÍPIOS DOS REGIMES DE BENS...................................................................38

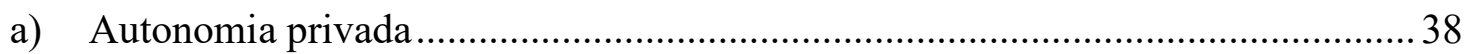

a.1) Variedade de tipos e liberdade de escolha............................................ 41

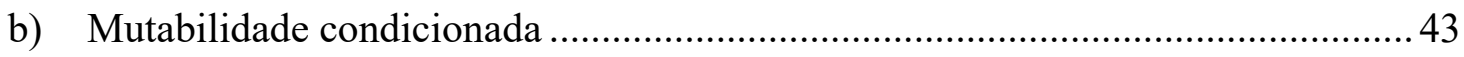

SEÇÃo V - PACTO ANTENUPCIAL ..........................................................................................5 50

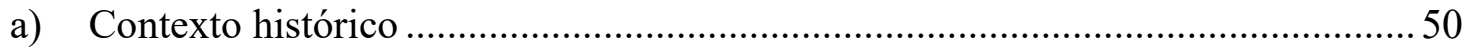

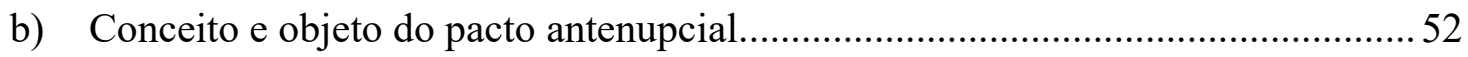

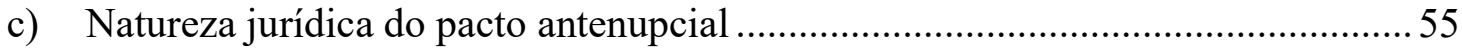

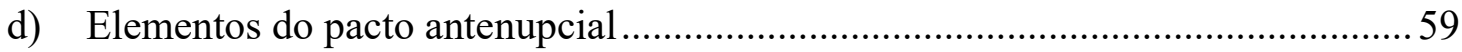

\section{CAPÍTULO II - REQUISITOS E EFEITOS DA ALTERAÇÃO DO REGIME DE}

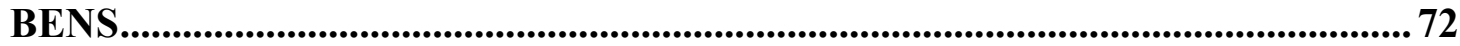

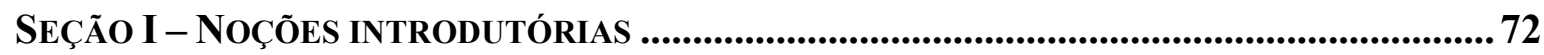

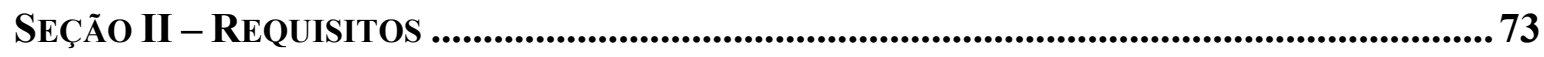

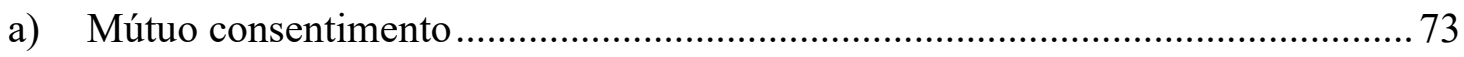

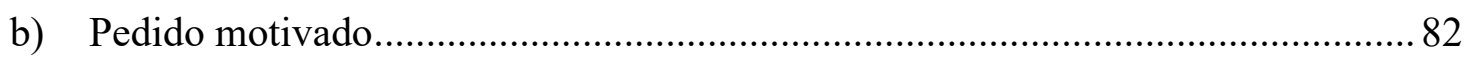

b.1) Alteração do regime da separação obrigatória de bens ............................ 93

b.2) Sociedade entre cônjuges - artigo 977 do Código Civil ........................... 97

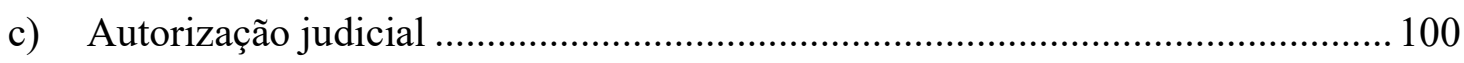

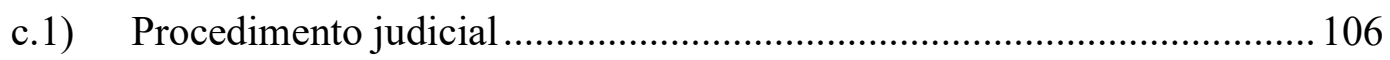


c.1.1) Intervenção do Ministério Público.............................................. 108

c.2) Limites à alteração de regime de bens.................................................... 111

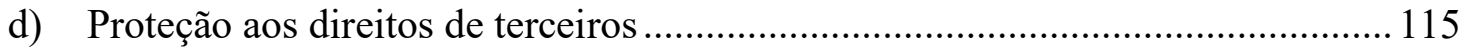

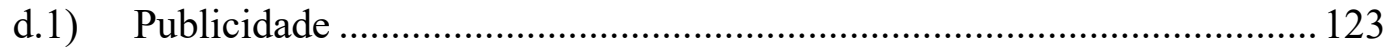

d.1.1) Publicação de editais e a utilização de outras formas de veiculação do pedido modificativo ........................................... 126

d.2) Inexistência de dívidas........................................................................... 130

d.3) Necessidade de novo pacto para alteração do regime de bens no casamento

SEÇ̃̃o V - EFICÁCIA DA ALTERAÇÃo do REGIME DE BENS ................................................136

a) Irretroatividade da alteração do regime de bens.................................................... 136

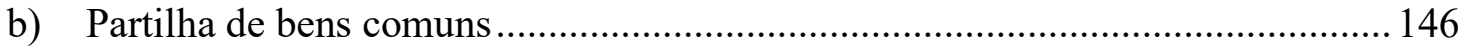

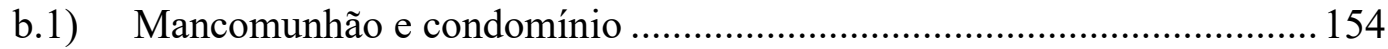

CAPÍTULO III - MUTABILIDADE DE REGIME DE BENS NO CASAMENTO E A QUESTÃO TEMPORAL ..................................................................................... 164

SEÇÃo I - NoÇÕES INTRODUTÓRIAS ........................................................................................164

SEÇÃO II - DIREITO INTERTEMPORAL .................................................................................... 164

Seção III - Teoria do Direito Adquirido versus Teoria das Situações JURÍDICAS: O DEBATE ENTRE GABBA E ROUBIER.........................................................170

a) A teoria do direito adquirido de Carlo Francesco Gabba...................................... 170

b) A teoria das situações jurídicas de PAUL RoubiER ............................................... 173

SEÇÃO IV - DIREITO INTERTEMPORAL BRASILEIRO ........................................................... 175

SEÇÃO V - DIREITO ADQUIRIDO .............................................................................................. 180

SEÇÃO VI - ATO JURÍDICO PERFEITO ................................................................................. 184

Seção IV - A extensão do artigo 2.039 do Código Civil de 2002 e a ALTERAÇ̃̃̃ DO REGIME DE BENS DE CASAMENTOS CELEBRADOS NA VIGÊNCIA DO

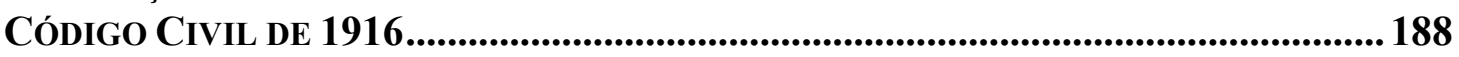

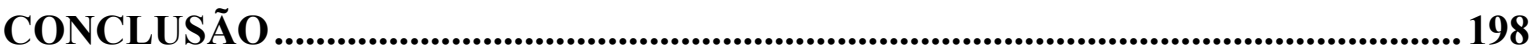

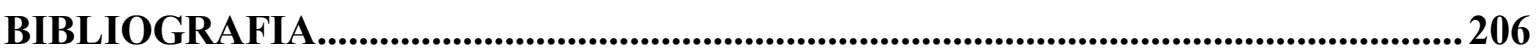





\section{INTRODUÇÃO}

A família reflete a realidade social em que se insere, fruto das influências religiosas, socioeconômicas e culturais de sua época. Segundo GISELDA HiRONAKA, as entidades familiares são uma realidade interligada com os rumos e os desvios da história. ${ }^{1}$

Até a edição do Código Civil de 2002, as leis que normatizaram o casamento refletiam a realidade patriarcal brasileira. Tanto é assim que, somente após o advento do Estatuto da Mulher Casada (Lei $\mathrm{n}^{\mathrm{o}}$ 4.121/1962), o cônjuge virago deixou de ser considerado relativamente incapaz e dependente do marido.

Em nosso ordenamento jurídico, o casamento sempre trouxe consigo um regime de bens, que serve como estatuto econômico da família. Em proteção aos direitos dos cônjuges hipossuficientes e de terceiros que contratavam com o casal, a preocupação quanto à sua alteração após as núpcias se tornou uma tônica em nossa experiência jurídica.

Com o passar do tempo, em consequência de uma maior complexidade nas relações sociais, a escolha do regime de bens e a verificação de sua viabilidade no dia a dia familiar tornaram-se extremamente complexas. Como não se pode prever as contingências da vida a dois, resguardar o patrimônio ante as circunstâncias da dinâmica da conjugalidade se tornou uma constante na advocacia de família, porque um regime de bens que se justificava preteritamente muitas vezes perde a sua razão de ser ou mesmo se torna prejudicial aos interesses dos cônjuges.

Apesar disso, durante muito tempo, acreditou-se que a proibição de alteração evitaria que pressões ao longo do casamento pudessem representar prejuízo a credores ou aos próprios cônjuges. Por isso, a intervenção nesta decisão familiar parecia justificar-se.

No entanto, após conquistas sociais, especialmente femininas, a doutrina, com especial destaque a ORLANDO GOMES, começou a defender a mutabilidade do regime de bens. $\mathrm{O}$ engessamento das relações familiares, inclusive patrimoniais, já não estava mais em consonância com o momento social.

Sobreveio a promulgação da Carta Política de 1988, que buscou a construção de um Estado Democrático de Direito, fundado na dignidade da pessoa humana, na igualdade

HIRONAKA, Giselda Maria Fernandes Novaes. Família e casamento em evolução. Revista Brasileira de Direito de Família, Porto Alegre: IBDFAM, v. 1, nº 1, p. 7, abr.-jun. 1999. 
material e no pluralismo. Essa concepção serviu de norte para a ordem jurídica, com reflexos posteriores no que viria a ser o Código Civil de 2002. Os efeitos disso no âmbito familiar foram diretos, garantindo a superação de antigos valores familiares, tornando-se a família um espaço de desenvolvimento da personalidade de seus integrantes e do afeto.

Dentro desse contexto, em 11 de janeiro de 2003, entrou em vigor o Código Civil de 2002, que, no artigo $1.639, \S 2^{\circ}$, previu a chamada mutabilidade justificada do regime de bens, mediante autorização judicial em pedido motivado de ambos os cônjuges, apurada a procedência das razões invocadas e ressalvados os direitos de terceiros. Foi igualmente previsto, no artigo 2.039 do Código Civil de 2002, que "o regime de bens nos casamentos celebrados na vigência do Código Civil anterior, Lei 3.071, de 1 de janeiro de 1916, é o por ele estabelecido".

Finalmente o Direito brasileiro adequou suas disposições legais ao momento social em que a família se encontrava. Optou-se por acompanhar aquilo que já vinha sendo aplicado em países como França, Itália e Alemanha.

Contudo, a mutabilidade do regime de bens se tornou tema bastante controvertido no Direito de Família atual, o que, em parte, explica-se pelas diversas interpretações dadas ao objetivo dispositivo legal que trata do assunto, inclusive com relação aos requisitos expressamente previstos no artigo 1.639, $\S 2^{\circ}$, do Código Civil.

A questão não se restringe a tanto. Um dos pontos tormentosos diz respeito ao termo inicial do novo regime de bens, isto é, se os efeitos da mudança seriam retroativos ou prospectivos. A depender da solução para o problema, podem ser colocados em xeque os interesses de terceiros juridicamente interessados, expressamente ressalvados por nosso legislador, em detrimento da autonomia privada dos cônjuges.

Não menos relevante é a divergência surgida a respeito da necessidade de liquidação do regime de bens alterado, com a partilha dos aquestos, sobre a qual a doutrina nacional ainda não se debruçou com a devida profundidade. Sobre a questão, não há qualquer menção legal, nem mesmo no Código de Processo Civil de 2015, que tratou da mudança do regime de bens em seu artigo 734 .

Ainda com a superveniência da possibilidade de alteração do regime patrimonial, muitos casais que celebraram o matrimônio na vigência do Código Civil de 1916 buscaram modificar o regime de bens de seu casamento, o que gerou dúvida a respeito do conflito de leis no tempo em relação à possibilidade de alteração do regime de 
bens. Nesse passo, o questionamento a esse respeito foi acerca da possibilidade de a lei nova, autorizadora da alteração do regime de bens, regular os atos praticados sob a vigência da lei anterior.

Por fim, há controvérsia acerca do próprio procedimento de alteração de regime de bens. Pretendendo evitar excessos por parte dos cônjuges, o Código Civil exigiu a autorização judicial em pedido motivado de ambos os cônjuges. No entanto, a discussão ganhou mais fôlego com a sanção do Código de Processo Civil de 2015, o qual incluiu o pedido judicial de alteração de regime de bens matrimonial no rol de ações de jurisdição voluntária e determinou, no artigo 734 , um procedimento específico para a modificação com mais requisitos do que a legislação civilista dispunha.

Para muitos doutrinadores, ${ }^{2}$ a previsão legal ratifica uma ingerência estatal desnecessária no âmbito da autonomia privada dos cônjuges, reforçando seus argumentos com uma analogia ao divórcio, que pode ser feito extrajudicialmente, enquanto, para outros, ${ }^{3}$ ela confirma o princípio da mutabilidade justificada do regime de bens.

No embate entre autonomia privada e ordem pública no âmbito das relações patrimoniais de família, ainda se extrai discussão acerca da possibilidade de cônjuges casados pelo regime da separação obrigatória de bens afastarem, por comum acordo, a imposição legal, o que deverá ser objeto do estudo ora apresentado.

Apesar de a família ter se tornado base da sociedade e, por consequência, passível de especial proteção estatal, os núcleos familiares tornaram-se livres para perseguir a realização pessoal de seus integrantes, valorizando as liberdades individuais. Essa dicotomia acarretou um embate entre a esfera da autonomia privada dos indivíduos e a ordem pública no âmbito familiar, surgindo dúvida sobre em que medida o legislador pode ordenar as relações patrimoniais de família e, da mesma forma, até onde o Estado, no caso concreto, deve integrar a vontade das partes.

A mutabilidade do regime de bens apresenta uma série de desafios, pois as relações afetivas passam por uma ressignificação, com a necessidade de revisão de antigos paradigmas. Assim, diante das dificuldades supra-apresentadas, foi aberto caminho para o

2 Por todos: DIAS, Maria Berenice. Manual de direito das famílias. 11. ed. São Paulo: Revista dos Tribunais, 2016. p. 330.

3 Por todos: SANTOS, Luiz Felipe Brasil. A mutabilidade dos regimes de bens. Disponível em: $<$ http://www.migalhas.com.br/dePeso/16,MI2295,101048A+mutabilidade+dos+regimes+de+bens $>$. Acesso em: 11 nov. 2015. 
surgimento de inúmeros questionamentos acerca da mutabilidade do regime de bens, instituto relativamente novo no sistema jurídico brasileiro.

As controvérsias referidas anteriormente representam apenas uma parte da dificuldade que a mutabilidade do regime de bens significa atualmente, não esgotando, obviamente, as dúvidas acerca do tema, que serão apresentadas ao longo da presente dissertação de mestrado. Por tudo isso, é evidente a necessidade de o assunto receber a devida atenção da doutrina e da jurisprudência, até porque a sua utilização exige uma delimitação clara e objetiva acerca de sua aplicação, por meio de um estudo aprofundado, o que, desde já, a dissertação de mestrado se propõe a realizar.

A pesquisa realizada é teórica, desenvolvida, de um lado, pelo método dedutivo, principalmente através de revisão bibliográfica, com o objetivo de demonstrar as consequências lógicas dos conceitos estudados; de outro, indutivo-analógico, partindo do estudo de casos de alteração de regime de bens, bem como de eventuais conflitos que isto pode representar, sobretudo em face da ordem pública e do interesse dos próprios cônjuges e de terceiros, para daí extrair soluções aos problemas verificados. 


\section{CONCLUSÃO}

Como inicialmente afirmado, a presente dissertação teve por objetivo examinar o tratamento dado à alteração do regime de bens no curso do casamento pelo ordenamento jurídico brasileiro, amparando-se na doutrina e na legislação nacional e estrangeira. Mais do que exaurir a análise das questões atinentes ao assunto, a consciência a seu respeito foi o motivo que impulsionou o seu estudo.

Complementando as conclusões apresentadas no curso do trabalho, podem ser apresentadas as seguintes conclusões:

1. O regime de bens é de todo relevante para o casamento, na medida em que, por meio dele, são resolvidas as questões patrimoniais do casal, como a titularidade de bens e a sua comunicabilidade, com efeitos inclusive perante seus sucessores e terceiros. A sua escolha é uma prerrogativa dos cônjuges, daí por que se reconhece como princípios dos regimes de bens a autonomia privada, da qual decorre a variedade de tipos e a liberdade de escolha, e a mutabilidade condicionada.

2. No regime da separação obrigatória de bens, questão relevante diz respeito à incidência da Súmula 377 do Supremo Tribunal Federal, editada no ano de 1964 em função da previsão do artigo 259 do Código Civil de 1916, a qual determina a comunicabilidade dos aquestos, no fito de mitigar os efeitos do regime, quando a imposição se dá em função da idade dos cônjuges. A aplicação do conteúdo sumulado se justifica como um esforço extralegislativo de evitar injustiças, na medida em que reduz o âmbito operativo da norma prevista pelo legislador. Da mesma forma, justifica-se a redação do Enunciado 261 da III Jornada de Direito Civil.

Aplicando-se a Súmula 377, ainda desponta a discussão a respeito da necessidade de comprovação do efetivo esforço comum para que haja a partilha dos aquestos. Nesse sentido, é equivocado o entendimento mais recente do Superior Tribunal de Justiça no sentido de ser necessária a comprovação do esforço comum, pois acaba por encaminhar o desfecho do impasse para o campo da sociedade de fato e afronta o próprio conteúdo da Súmula. Pela redação dada pelo Supremo Tribunal Federal, a aplicação do conteúdo sumulado leva à presunção absoluta do esforço comum, ainda que isso leve a uma aproximação do regime obrigatório com o regime supletivo. 
A par dessa árida discussão, não há como se defender a permanência do regime obrigatório de bens em função do critério etário. Deveria o legislador ter superado a visão preconceituosa de presumir a vulnerabilidade dos indivíduos em função de sua idade, o que, ao fim e ao cabo, colocaria verdadeira pá de cal na insegurança criada nos cônjuges casados em tais circunstâncias.

3. O instrumento jurídico para manifestação de vontade acerca das consequências patrimoniais do casamento é o pacto antenupcial, lavrado em tabelionato, antes da celebração do casamento. Trata-se de um negócio jurídico de Direito de Família, porque decorrente da vontade dos nubentes e previsto pelo ordenamento jurídico, destinando-se a um fim passível de proteção jurídica, o casamento - sua conditio iuris.

O objeto do pacto antenupcial é a escolha do estatuto patrimonial do casamento, o que lhe garante força normativa. No entanto, nada impede que sejam incluídas na escritura pública cláusulas de natureza extrapatrimonial, mas estas devem ser consideradas elementos estranhos ao pacto, justificando-se a sua inclusão por coligação voluntária expressa.

Quanto à capacidade dos agentes, é fundamental apontar que a escolha do regime de bens é prerrogativa exclusiva dos nubentes. Tanto é assim que o legislador previu a incidência do regime da separação obrigatória de bens para os casamentos celebrados por menores de idade. No entanto, o mesmo cuidado não se teve, após a entrada em vigor do Estatuto da Pessoa com Deficiência (Lei n ${ }^{\circ}$ 13.146/2015), com o casamento de incapazes, porque admitir que a escolha do curador importa contrariar a pessoalidade do casamento. Por isso, deveria haver previsão legal expressa a respeito da incidência do regime obrigatório para o casamento de pessoas incapazes.

Com relação à forma, conquanto a lei preveja expressamente a nulidade do pacto que não for feito por escritura pública, o requisito não se sustenta: a uma, porque o instrumento particular pode aumentar a utilização do pacto e, assim, conduzir as pessoas a refletirem mais sobre a escolha do regime de bens; a duas, porque a publicidade da escolha é dada não pelo pacto antenupcial em si, mas pela referência ao seu conteúdo na certidão de casamento, no Registro de Imóveis do primeiro domicílio dos cônjuges e na Junta Comercial, o que garante eficácia erga omnes ao regime de bens.

Dúvidas a respeito da caducidade ou pós-eficacização do pacto antenupcial, sobre as quais se debruça a doutrina, se resolvem no fato de que, para que haja validade 
das convenções antenupciais, deve haver vontade declarada das partes, tanto com relação à celebração do casamento, quanto em relação à escolha do regime de bens, devendo ser informada a existência de uma convenção.

Por outro lado, não se admite que o pacto antenupcial possa servir como contrato de convivência, na medida em que a ineficácia da avença é decorrência lógica da não celebração do matrimônio.

4. A mutabilidade do regime de bens é uma novidade no ordenamento jurídico brasileiro, pois só passou a ser admitida com a entrada em vigor do Código Civil de 2002. Os motivos para que a imutabilidade perdurasse tanto tempo em nossa experiência eram a proteção aos interesses dos cônjuges e de terceiros juridicamente interessados, bem como a ideia de perpetuidade do vínculo matrimonial.

Contudo, com o avançar do calendário e a repercussão dos reflexos das mudanças sociais na família, o único fundamento que ainda se sustentava para a manutenção da tradicional imutabilidade era a proteção de terceiros. Isso não foi descuidado pelo legislador de 2002, que, influenciado pela doutrina de Orlando Gomes, previu a proteção pela via da ineficácia da mudança.

5. O modelo de alteração justificada do regime de bens, adotado Código Civil de 2002, é bastante rígido. Isso pode ser justificado pelo apego à tradição e pelo receio dos efeitos da mudança.

6. O requisito do mútuo consentimento tem razão de ser, pois a escolha do regime de bens é negócio jurídico realizado pela convergência de duas vontades, não cabendo a um dos cônjuges impor ao outro a mudança, sob pena de afronta ao ato jurídico perfeito. Ainda que alguns ordenamentos jurídicos estrangeiros autorizem, em determinados casos, a alteração unilateral do regime de bens, essa não é a realidade brasileira.

A alteração do regime de bens é uma prerrogativa exclusiva dos cônjuges, assim como o é a escolha do regime de bens antes do casamento pelos nubentes. Por isso, não há que se falar em consentimento de outras pessoas, sejam eles eventuais credores, sejam eles partes que tenham participado da lavratura do pacto antenupcial. Da mesma forma, não é possível que a mudança de regime de bens conte com a intervenção do curador de um cônjuge incapaz ou do Ministério Público. 
7. A exigência de indicação dos motivos que levaram o casal a pretender a modificação do estatuto econômico de seu casamento deve ser vista com cautela. Além de ser descabida a invasão da privacidade dos consortes, tratando-se de um direito disponível de pessoas maiores e capazes, o grau de subjetividade que levou o casal a buscar a alteração muitas vezes não pode ser aferido judicialmente. Deve, por isso, ser respeitada a autonomia privada das partes, princípio incidente sobre a esfera patrimonial do Direito de Família, evitando-se uma invasão na privacidade do par e uma desnecessária exposição.

8. Nos casamentos regidos pelo regime da separação obrigatória de bens, superada a causa da imposição legal, nenhum óbice há para que se proceda à alteração do regime de bens. Isso porque a cominação de um regime de bens configura uma restrição ao direito dos cônjuges, de modo que não há fundamento jurídico para obrigar que os cônjuges continuem casados sob um regime imposto, até porque a razão para diferenciar o casal dos demais desapareceu.

9. No tocante à pretensão de alteração do estatuto patrimonial do casamento em função da previsão do artigo 977 do Código Civil, andou mal o legislador ao prever tal proibição. O patrimônio das pessoas físicas não se confunde com o das pessoas jurídicas, daí por que não haveria risco de burla ao regime de bens ou confusão patrimonial. Essa vedação, porém, não inclui os cônjuges casados antes da entrada em vigor do Código Civil de 2002, as sociedades constituídas antes de 11 de janeiro de 2003, assim como as sociedades constituídas entre um dos cônjuges e terceiros.

Por outro lado, se dois sócios vierem a se casar, apenas terão restrição quanto ao regime da comunhão universal, pois a separação obrigatória de bens é aplicável independentemente da vontade dos consortes, não estando configurada nenhuma hipótese de impedimento matrimonial ou de dissolução da sociedade.

10. O requisito da autorização judicial é passível de críticas, especialmente diante da realidade em que se encontra o Poder Judiciário brasileiro. A exigência tornou-se ainda mais insulada em nossa realidade após a entrada em vigor da Lei $\mathrm{n}^{\mathrm{o}} 11.441 / 2007$, que permitiu que divórcios e inventários fossem feitos extrajudicialmente.

O controle judicial pode ser considerado uma intromissão desnecessária na autonomia privada dos cônjuges. O pedido deve ser formulado por cônjuges capazes, envolve exclusivamente direitos disponíveis e não há litígio, não se vislumbrando motivo plausível para que a mudança não possa ser feita pela via cartorária. 
Por essas razões, espera-se que o Projeto de Lei $n^{\circ}$ 470/2013, o "Estatuto das Famílias" seja aprovado em breve, a fim de permitir que o procedimento modificativo possa ocorrer pela via cartorária.

11. A atuação do Ministério Público no procedimento de alteração do regime de bens não se justifica, porque está fora das atribuições constitucionais e legais do referido Órgão. Dessa forma, ainda que o artigo 734, $\S 1^{\circ}$, do Código de Processo Civil preveja a intervenção do Parquet no procedimento modificativo, como gozam de autonomia e independência funcional, os membros do Ministério Público podem se abster de intervir, conforme o Ato nº 313/03-PGJ-CGMP do Ministério Público de São Paulo.

12. O Direito brasileiro não prevê nenhum óbice ao número de alterações do regime de bens em um mesmo casamento, assim como não dispõe sobre prazo mínimo para a vigência de determinado regime de bens. Assim, podem os cônjuges apresentar pedido de alteração do estatuto patrimonial de seu matrimônio quantas vezes e quando entenderem necessário.

13. A solução dada pelo legislador pátrio no fito de proteger os interesses de terceiros que possam ser prejudicados pela alteração do regime de bens pela via da ineficácia é acertada. Como o patrimônio do devedor é a garantia de satisfação do crédito, a questão é de todo relevante, na medida em que há a necessidade de evitar fraude contra credores e proteger o tráfego jurídico. Os terceiros não podem ficar expostos a alterações de regime de bens que poderão lhe impingir prejuízos.

14. Como são estranhos à eleição do regime de bens, os terceiros não podem se insurgir contra a mudança. Assim, se não podem ser prejudicados pelo novo arranjo patrimonial estabelecido entre os cônjuges, devem respeitar a pretensão dos consortes, daí por que a exigência de publicação de editais antes do deferimento da alteração é equivocada, bem como qualquer medida que vise a dar publicidade prévia à mudança.

O trânsito em julgado da sentença que autoriza a mudança do regime de bens dá efeitos, entre o casal e seus herdeiros, ao novo regime. Contra terceiros, a mudança só é eficaz após a devida publicidade, por meio da averbação da alteração na certidão de casamento, no registro de imóveis do domicílio dos cônjuges, nas matrículas dos imóveis de propriedade dos consortes e na Junta Comercial.

15. Da mesma forma, se a mudança de regime de bens é ineficaz contra terceiros juridicamente interessados, não se pode exigir dos cônjuges a comprovação da inexistência 
de dívidas. A alteração jamais frustrará o crédito de terceiros, porque estão expressamente ressalvados na previsão do artigo $1.639, \S 2^{\circ}$, do Código Civil.

16. A necessidade de elaboração de novo pacto é medida excessiva. A redação do artigo 1.639, $\S 2^{\circ}$, do Código Civil e do artigo 734, $\S 2^{\circ}$, do Código de Processo Civil não exige a lavratura do documento público, até porque, ao deduzirem o pedido modificativo, os cônjuges devem indicar as regras do regime de bens que pretendem adotar, sob pena de inépcia da inicial.

Veja-se que o pacto antenupcial está expressamente previsto no artigo 1.640, parágrafo único, do Código Civil, não havendo, por outro lado, exigência de pacto para a alteração do regime de bens. A forma solene deve ser expressamente prevista, porque se trata de exceção, sendo a forma livre para prática dos negócios jurídicos a regra em nosso ordenamento jurídico.

Além disso, o pacto nupcial produziria os mesmos efeitos do mandado judicial, que igualmente serve para averbação nos registros, a fim de garantir a publicidade da sentença.

17. Não há como se defender a retroatividade da alteração do regime de bens, na medida em que o ato jurídico perfeito é tutelado constitucionalmente e só há ressalva aos direitos de terceiros se a alteração tiver eficácia prospectiva. Se assim não fosse, os negócios jurídicos praticados antes da mudança poderiam ser atingidos pela mudança, em prejuízo de credores.

Ademais, o efeitos prospectivos independem das características do regime de bens modificado e daquele para o qual haverá a modificação. Não há, ainda, nenhum impedimento para que o casamento seja regido por dois estatutos patrimoniais diferentes sem que isso configure um regime híbrido de bens -, até porque a retroatividade é exceção no Direito brasileiro.

18. A partilha em decorrência da mudança de regime de bens no casamento jamais foi cogitada durante os trabalhos legislativos que resultaram na aprovação do artigo $1.639, \S 2^{\circ}$, do Código Civil. Em nossa experiência jurídica, o regime patrimonial só se extinguia pela morte, divórcio, separação, nulidade ou anulação do casamento.

Assim, não havendo previsão legal determinando a partilha de bens, não há como se impor que os cônjuges assim procedam, sobretudo porque a liquidação do regime de bens anterior com a partilha dos aquestos parece reforçar a ideia de retroatividade do 
regime de bens, que não confere com a nossa ordem jurídica. Por outro lado, como também não há vedação expressa, a partilha de bens pode ser considerada lícita, porque não se encontra em conflito com a ordem jurídica.

Nessa linha, novamente deve ser privilegiada a incidência do princípio da autonomia privada no âmbito patrimonial de Direito de Família, motivo pelo qual o desejo dos consortes deve ser preservado, como já se manifestou o Superior Tribunal de Justiça no julgamento do Recurso Especial n ${ }^{\circ} 1.533 .179 / \mathrm{RS}$.

Contudo, caso os consortes pretendam a partilha de bens no curso do casamento, deve ser facultado aos terceiros juridicamente interessados a oposição ao plano de partilha. Se a alteração do regime de bens é ineficaz perante os credores em decorrência de previsão legal, a partilha não o é, podendo impingir prejuízos de ordem patrimonial a esses terceiros. Exclusivamente nesse caso, justifica-se a veiculação de editais ou utilização de outros meios que garantam publicidade ao pedido de partilha, assim como a comprovação da inexistência de dívidas capazes de gerar a insolvência do devedor.

19. Entre o período que vai da alteração do regime de bens e a ultimação da partilha dos aquestos, os bens permanecem entre os cônjuges na forma de mancomunhão, porque a extinção do regime de bens não dá fim ao estado de indivisão dos bens. Somente a partilha é capaz de decotar as meações. Isso porque, diferentemente do condomínio, em que neste cada um dos titulares detém a parte ideal da coisa comum, com iguais direitos ao uso do bem, podendo alienar sua parte sobre a coisa comum, no estado de mancomunhão há uma massa patrimonial única, que não pode ser individualizada, não se podendo destacar bens específicos para que comporem cada uma das meações.

21. O artigo 2.039 versa sobre o regime adotado pelas partes. Trata-se de uma garantia aos cônjuges casados sob a égide do Código Civil de 1916 de que seu regime de bens mantém-se caso não busquem a sua alteração. A redação do dispositivo legal não pode ser lida como se houvesse uma determinação para que pares casados antes de 11 de janeiro de 2003 não pudessem buscar a alteração do estatuto econômico de seu casamento.

Se não bastasse isso, como a eficácia do casamento é continuada, incide na hipótese em estudo a previsão do artigo 2.035 do Código Civil de 2002, a qual dispõe que a validade dos atos praticados com base na codificação anterior é por ele regulamentada, enquanto sua eficácia está condicionada à lei em vigor, em consonância com o direito intertemporal brasileiro. 
22. Deve-se ter presente a necessidade de a lei não impor restrições desnecessárias para a mudança do regime de bens, como se verifica atualmente, sob pena de a mutabilidade do regime de bens se tornar letra morta em nosso ordenamento jurídico, sendo mais fácil que os cônjuges adotem vias oblíquas para atingirem o seu fim. 


\section{BIBLIOGRAFIA}

AGUIRRE, João. O Estatuto da Pessoa com Deficiência protege o incapaz? SIM. Disponível em: $<$ http://www.cartaforense.com.br/conteudo/artigos/o-estatuto-dapessoa-com-deficiencia-protege-o-incapaz-sim/15732>. Acesso em 15.11.2018.

ALMEIDA, José Luiz Gavião de. Direito civil: família. Rio de Janeiro: Elsevier, 2008.

ALVES, João Luiz. Código Civil da República dos Estados Unidos do Brasil. Rio de Janeiro: Borsoi, 1957. V. 1.

ANDRADE, Fábio Siebeneichler de; PAIVA, Franscisa Juliana Castello Branco Evaristo de. A disciplina da mutabilidade do regime de bens no direito civil brasileiro: conciliação entre exercício da autonomia privada dos cônjuges e visão institucionalista do casamento. Revista da AJURIS, Porto Alegre, v. 42, nº 139, p. 87-112, dez. 2015.

ANTUNES VARELA, João de Matos. Das obrigações em geral. 10. ed. Coimbra: Almedina, 2000.

. Direito da família. 4. ed. Lisboa: Livraria Petrony, 1996. v.1.

ASCENSÃO, José de Oliveira. $O$ direito: introdução e teoria geral. 11. ed. Coimbra: Almedina, 2001.

ÁVILA, Humberto. Segurança jurídica no direito tributário. Tese (Titularidade de Professor de Direito Tributário). São Paulo: Universidade de São Paulo, 2009.

. Teoria da segurança jurídica. São Paulo: Malheiros, 2011.

AZEVEDO, Álvaro Villaça. União estável: antiga forma de casamento de fato. Revista de Direito Civil, Imobiliário, Agrário e Empresarial, São Paulo: Revista dos Tribunais, v. 20, no 77, p. 11-17, jul.-set. 1996.

. Teoria geral dos contratos típicos e atípicos. 3. ed. São Paulo: Atlas, 2009.

; PAPA DOS SANTOS, Regina Beatriz. Sugestões ao Projeto de Código Civil: Direito de família (Projeto de Lei de Câmara 118, de 1984, em tramitação perante o Senado Federal): 2. ${ }^{\text {p }}$ parte. Revista dos Tribunais, v. 731, p. 11-47, set. 1996.

AZEVEDO, Antônio Junqueira de. Negócio jurídico: existência, validade e eficácia. 4. ed. São Paulo: Saraiva, 2002. 
- Retrocesso no direito de família. In: Revista da Faculdade de Direito da Universidade de São Paulo, São Paulo, v. 93, p. 111-114, jan.-dez. 1998.

. Negócio jurídico e declaração negocial: noções gerais e formação da declaração negocial. São Paulo, 1986.

BARBOZA, Heloísa Helena. Alteração do regime de bens e o art. 2.039 do Código Civil. Anais - IV Congresso Brasileiro de Direito de Família. Belo Horizonte: Del Rey, 2004.

BEVILAQUA, Clovis. Codigo Civil dos Estados Unidos do Brasil comentado. Rio de Janeiro: Ed. Paulo de Azevedo, 1949. v.1.

. Codigo Civil dos Estados Unidos do Brasil comentado. Rio de Janeiro: Ed. Paulo de Azevedo, 1950. v. 2.

BERNINI, A.; BRUGNETTINI, L.; COLUCCI, V.; DE FILIPPIS, B.; DRAKE, M.; GIARNIERI, E.; GUERRA, F.; GURZILLO, I.; KING, F.; MAZZEI, F.; MONEGAT, M.; PAESANO, G.; PINI, M.; TIRINI, M.; TROTTA, G. Il regime patrimoniale dela famiglia, la comunione legale ed il trust. Padova: CEDAM, 2011.

BETTI, Emilio. Teoria geral do negócio jurídico. Coimbra: Coimbra Ed., 1969. t. 1.

. Teoria geral do negócio jurídico. Coimbra: Coimbra Ed., 1969. t. 2.

BIAZI, João Pedro de Oliveira de. Pacto antenupcial: uma leitura à luz da teoria do negócio jurídico. Revista Jurídica Luso Brasileira, ano 2, nº 1, p. 229-264, 2016.

BITTAR, Carlos Alberto. Direito de família. 2. ed. Rio de Janeiro: Forense Universitária, 2006.

BOSSERT, Gustavo A.; ZANNONI, Eduardo A. Manual de derecho de familia. 6. ed. Buenos Aires: Astrea, 2010.

BRANDÃO, Débora Vanessa Caús. Regime de bens no novo Código Civil. São Paulo: Saraiva, 2007.

BRANDELLI, Leonardo. Teoria geral do direito notarial. São Paulo: Saraiva, 2009.

BUNAZAR, Maurício. Obrigação propter rem: aspectos teóricos e práticos. São Paulo: Atlas, 2014.

CAHALI, Francisco José. A súmula 377 e o novo Código Civil e a mutabilidade do regime de bens. Revista do Advogado, ano XXIV, nº 76, jun. 2004.

CAHALI, Yussef Said. Fraude contra credores. 2. ed. São Paulo: Revista dos Tribunais, 1999. 
CAIS, Fernando Fontoura da Silva. Direito processual civil intertemporal. Tese (Doutorado em Direito). São Paulo: Universidade de São Paulo, 2010.

CAMARGO NETO, Mario de Carvalho. Alteração Administrativa de Regime de Bens, Mediante Escritura Pública. Estatuto das Famílias. Disponível em: $<$ http://www.ibdfam.org.br/_img/artigos/Altera\%C3\%A7\%C3\%A3o\%20Regime\%20 M\%C3\%A1rio.pdf>. Acesso em: 19 jan. 2016.

CAMPOS, Diogo Leite de. Lições de direito de família e das sucessões. 2. ed. Coimbra: Almedina, 2010.

CANUTO, Érica Verícia de Oliveira. A mutabilidade do regime de bens no casamento. Dissertação (Mestrado em Direito). Salvador: Universidade Federal da Bahia, 2006.

CARDOSO, Fabiana Domingues. Regime de bens e pacto antenupcial. São Paulo: Método, 2010.

CARDOZO, José Eduardo Martins. Da retroatividade da lei. São Paulo: Revista dos Tribunais, 1995.

CARNEIRO, Rafael Jabur. Sociedade entre cônjuges no Código Civil (artigo 977). Dissertação (Mestrado em Direito). São Paulo: Universidade de São Paulo, 2008.

CARVALHO, Dimas Messias de. Direito das famílias. 3. ed. Lavras: Unilavras, 2014.

CARVALHO, João Andrades. Regime de bens. Rio de Janeiro: AIDE, 1996.

CARVAlHO SANTOS, J. M. de. Código civil brasileiro interpretado. 5. ed. Rio de Janeiro: Freitas Bastos, 1953. v. 1.

4.

. Código civil brasileiro interpretado. 5. ed. Rio de Janeiro: Freitas Bastos, 1953. v.

CASSETTARI, Christiano. Elementos do direito civil. 4. ed. São Paulo: Saraiva, 2016.

CHINELLATO, Silmara Juny de Abreu. A mutabilidade do regime de bens entre cônjuges no Código Civil de 2002. Revista Jurídica do Uniaraxá, Araxá, ano 10, nº 9, p. 345367, 2006.

. Comentários ao Código Civil: parte especial do direito de família: filiação; adoção poder familiar; regime de bens (comunhão universal; comunhão parcial; participação final nos aquestos; separação); alimentos; usufruto e administração dos bens de filhos menores (arts. 1.591 a 1.710). Antonio Junqueira de Azevedo (Coord.). 2. ed. São Paulo: Saraiva, 2007. v. 18.

COELHO, Francisco Pereira; OLIVEIRA, Guilherme de. Curso de direito da família. 4. ed. Coimbra: Coimbra Ed., 2008. v. 1. 
CORNU, Gérard. Les régimes matrimoniaux. 9. ed. Paris: Presses Universitaires de France, 1997.

COSTALUNGA, Karime. Direito de herança e separação de bens: uma leitura orientada pela Constituição e pelo Código Civil. São Paulo: Quartier Latin, 2009.

DANTAS, San Tiago. Direitos de família e das sucessões. 2. ed. Rio de Janeiro: Forense, 1991.

DELGADO, Mário Luiz. Novo direito intertemporal brasileiro. 2. ed. Saraiva: São Paulo, 2014.

DIAS, Maria Berenice. Manual de direito das famílias. 11. ed. São Paulo: Revista dos Tribunais, 2016.

DÍEZ-PICAZO, Luis; GULLÓN, Antonio. Sistema de derecho civil. Madrid: Tecnos, 2008. v. 4.

DINIZ, Maria Helena. Comentários ao Código Civil: parte especial: Das disposições finais e transitórias (arts. 2.028 a 2.046). Antonio Junqueira de Azevedo (Coord.). São Paulo: Saraiva, 2003. v. 22.

. Curso de direito civil brasileiro: direito de família. 26. ed. São Paulo: Saraiva, 2011. v. 5.

. Curso de direito civil brasileiro: direito de empresa. 26. ed. São Paulo: Saraiva, 2011. v. 8.

ESPÍNOLA, Eduardo; ESPÍNOLA FILHO, Eduardo. A Lei de Introdução ao Código Civil brasileiro. São Paulo: Renovar, 1999. v. 1.

FACHIN, Luiz Edson. Elementos críticos do direito de família. Rio de Janeiro: Renovar, 1999.

FARIAS, Cristiano Chaves de; ROSENVALD, Nelson. Curso de direito civil: famílias. 7. ed. Salvador: JusPodium, 2015. v. 6.

FERRAZ JÚNIOR, Tércio Sampaio. Sigilo de dados: o direito à privacidade e os limites à função fiscalizadora do Estado. Cadernos de Direito Constitucional e Ciência Política, São Paulo: Revista dos Tribunais, ano 1, p. 77-90, 1992.

FERREIRA, Cristiana Sanchez Gomes. O pacto antenupcial no Brasil à luz do direito e economia. Revista Jurídica Luso Brasileira, v. 2, nº 3, p. 415-444, 2016.

FERREIRA, Paulo Gaiger. Pactos patrimoniais e atividade notarial. In: DA SILVA, Regina Beatriz Tavares; CAMARGO NETO, Theodureto de Almeida Camargo. Grandes temas de direito de família e das sucessões. São Paulo: Saraiva, 2011. 
FERRI, Luigi. L'autonomia privata. Giuffrè: Milano, 1959.

FONSECA, Priscila M. P. Corrêa da; SZTAJN, Rachel. Código Civil comentado: direito de empresa: arts. 887 a 926 e 966 a 1.195. São Paulo: Atlas, 2008. v. 16.

FIUZA, César; POLI, Luciana Costa. Autonomia privada e intervenção no Estado Democrático de Direito: a (im)possibilidade de casamento entre homossexuais. Revista Brasileira de Estudos Políticos, Belo Horizonte: Universidade Federal de Minas Gerais, no 106, p. 95-132, jan.-jun. 2013.

GABBA, Carlo Francesco. Teoria dela retroattivitá delle leggi. 2. ed. Torino: Unione Tipografico Editrice, 1891.

GAGLIANO, Pablo Stolze; PAMPLONA FILHO, Rodolfo. Novo curso de direito civil. 2. ed. São Paulo: Saraiva, 2012. v. 6.

GALGANO, Francesco. Il negozio giuridico. 2. ed. Milão: Giuffrè Editore, 2002.

GODOY, Claudio Luiz Bueno de. Função social do contrato. 3. ed. São Paulo: Saraiva, 2009.

GOMES, Orlando. A reforma do Código Civil. Salvador: Publicações da Universidade da Bahia, 1965.

. Contratos. 18. ed. Rio de Janeiro: Forense, 1998.

. Direito de família. 5. ed. Rio de Janeiro: Forense, 1983.

. Direitos reais. 8. ed. Rio de Janeiro: Forense, 1983.

GONÇALVES, Carlos Roberto. Direito civil brasileiro. 5. ed. São Paulo: Saraiva, 2008. v. 6.

GOZZO, Débora. Pacto antenupcial. São Paulo: Saraiva, 1992.

. Patrimônio no casamento e na união estável. In: Aspectos controvertidos do novo Código Civil: escritos em homenagem ao Ministro José Carlos Moreira Alves. São Paulo: Revista dos Tribunais, 2003.

GUEDES, Jefferson Carús. Comentários ao Código de Processo Civil: artigos 719 ao 770. São Paulo: Revista dos Tribunais, 2017. v. 11.

HIRONAKA, Giselda Maria Fernandes Novaes. Casamento e regime de bens. In: ARRUDA ALVIM; CÉSAR, Joaquim Portes de Cerqueira; ROSAS, Roberto (Coord.). Aspectos controvertidos do novo Código Civil: escritos em homenagem ao Ministro Joé Carlos Moreira Alves. São Paulo: Revista dos Tribunais, 2003. 
. Família e casamento em evolução. Revista Brasileira de Direito de Família, Porto Alegre: IBDFAM, v. 1, nº 1, abr.-jun. 1999.

JUNQUEIRA DE AZEVEDO, Antonio. Retrocesso no direito de família. Revista da Faculdade de Direito da Universidade de São Paulo, São Paulo, v. 93, p. 111-114, jan.-dez. 1998.

KREUZ, Sérgio Luiz. Princípio da Imutabilidade do Regime de Bens do Casamento no Direito Brasileiro. Revista de Direito Privado, São Paulo: Revista dos Tribunais, v. 11, p. 264-317, maio-jun. 2001.

LAGRASTA NETO, Caetano; TARTUCE, Flávio; SIMÃO, José Fernando. Direito de família: novas tendências e julgamentos emblemáticos. 2. ed. São Paulo: Atlas, 2012. LEVADA, Filipe Antônio Marchi. Direito intertemporal e a proteção do direito adquirido. Curitiba: Juruá, 2011.

LIMONGI, Viviane Cristina de Souza. A capacidade civil e o Estatuto da Pessoa com Deficiência. Rio de Janeiro: Lumen Juris, 2018.

LIMONGI FRANÇA, Rubens. A irretroatividade das leis e o direito adquirido. 4. ed. São Paulo: Revista dos Tribunais, 1994.

LÔBO, Paulo Luiz Netto. A repersonalização das relações de família. In: BITTAR, Carlos Alberto (Coord.). O direito de família e a Constituição de 1988. São Paulo: Saraiva, 1989.

- Código Civil comentado: direito de família, relações de parentesco, direito patrimonial: arts. 1.591 a 1.693. São Paulo: Atlas, 2003. v. 16.

. Comentários ao Código Civil: parte especial: das várias espécies de contrato: da compra e venda; da troca ou permuta; do contrato estimatório; da doação (arts. 481 a 564). Antonio Junqueira de Azevedo (Coord.). São Paulo: Saraiva, 2003. v. 6.

. Direito civil: famílias. 4. ed. São Paulo: Saraiva, 2011.

LUCCA, Newton de et al. Comentários ao Código Civil brasileiro. Rio de Janeiro: Forense, 2005.

MADALENO, Rolf. Curso de direito de família. 5. ed. Rio de Janeiro: Forense, 2013.

O direito adquirido e o regime de bens. Revista Jurídica, Sapucaia do Sul: Notadez, n 348, out. 2006.

MALUF, Adriana Caldas do Rego Freitas Dabus; MALUF, Carlos Alberto Dabus. Curso de direito de família. São Paulo: Saraiva, 2013. 
MANFRÉ, José Antonio Encinas. Regime patrimonial de bens no novo Código Civil. São Paulo: Juarez de Oliveira, 2003.

MARINO, Francisco Paulo de Crescenzo. Contratos coligados no direito brasileiro. São Paulo: Saraiva, 2009.

MARTINS, Ronaldo Álvaro Lopes. A imutabilidade do regime de bens do casamento. Revista da EMERJ, Rio de Janeiro, v. 6, nº 24, p. 277-284, 2003.

MARTINS-COSTA, Judith. A boa-fé no direito privado: critérios para a sua aplicação. São Paulo: Marcial Pons, 2015.

MATHIAS, Maria Ligia Coelho; LOURENÇO, José. Efeitos ex tunc e ex nunc na mudança de regime de bens no casamento e na união estável. Revista Jurídica LusoBrasileira, ano 3, n. 1, p. 509-544, 2017, on-line.

MATTIA, Fábio Maria de. Regime de bens entre os cônjuges: estudo comparativo entre o Código Civil e o projeto de Código Civil e o projeto de Código Civil de 1975. Revista de Direito Civil, Imobiliário, Agrário e Empresarial, São Paulo: Revista dos Tribunais, v. 10, p. 105-121, out.-dez. 1979.

MAXIMILIANO, Carlos. Direito intertemporal ou teoria da retroatividade das leis. 2. ed. Rio de Janeiro: Freitas Bastos, 1955.

. Hermenêutica e aplicação do direito. Rio de Janeiro: Forense, 1980.

MELLO, Marcos Bernardes de. Teoria do fato jurídico: plano da existência. 13. ed. São Paulo: Saraiva, 2007.

MONTEIRO, Washington de Barros. Curso de direito civil: direito das coisas. 32. ed. São Paulo: Saraiva, 1995.

; SILVA, Regina Beatriz Tavares da. Curso de direito civil: direito de família. 39. ed. São Paulo: Saraiva, 2009. v. 2.

MOREIRA, José Cláudio Domingues; CANELLAS, Cristiane Maria da Costa; NUNES, Lydia Neves Bastos Telles. Inconstitucionalidade da exigência de apresentação das razões dos cônjuges como uma das condições para a mutabilidade do regime de bens. Anais do XV Congresso Nacional do CONPEDI. Florianópolis: Jose Arthur Boiteux, 2006.

MOTTA, Carlos Dias. Direito matrimonial e seus princípios jurídicos. 2. ed. São Paulo: Revista dos Tribunais, 2009.

NADER, Paulo. Curso de direito civil: direito de família. 3. ed. Rio de Janeiro: Forense, 2009. 
NALINI, José Renato. Comentários ao Código Civil: livro complementar das disposições finais e transitórias. Sálvio de Figueiredo Teixeira (Coord.). Rio de Janeiro: Forense, 2007. v. 22.

NERY, Rosa Maria de Andrade. Instituições de direito civil: família. São Paulo: Revista dos Tribunais, 2015.

NOGUEIRA, Luiz Fernando Valladão; NOGUEIRA, Lucila Carvalho Valladão. A mutabilidade do regime de bens sob a ótica das novas regras constitucionais (após EC 66/10). In: NOGUEIRA, Luiz Fernando Valladão. Regime de bens: direito de família e sucessões. Belo Horizonte: Del Rey, 2015. p. 119-140.

NORONHA, Fernando. Direito das obrigações. São Paulo: Saraiva, 2003. v. 1.

. Indispensável reequacionamento das questões fundamentais de direito intertemporal. Revista dos Tribunais, São Paulo, v. 94, no 837, p. 55-78, jul. 2005.

- Retroatividade, eficácia imediata e pós-atividade das leis: sua caracterização correta, como indispensável para solução dos problemas de direito intertemporal. Cadernos de Direito Constitucional e Ciência Política, São Paulo, v. 6, nº 23, p. 91110, abr.-jun. 1998.

NUNES, Lydia Neves Bastos Telles. A alteração do regime de bens autorizada judicialmente: como proceder para que ela produza efeitos? Revista do Instituto de Pesquisas e Estudos, Bauru, no 44, p. 369-378, set.-dez. 2005.

. Direito de familia: regimes matrimoniais de bens. Leme: J. H. Mizuno, 2005.

OLIVEIRA, Euclides de. Alteração do regime de bens no casamento. In: DELGADO, Mário Luiz; ALVES, Jones Figueirêdo. Novo Código Civil: questões controvertidas. São Paulo: Método, 2006. v. 1.

OLIVEIRA, Guilherme. A nova lei do divórcio. Lex Familiae - Revista Portuguesa de Direito da Família, Coimbra: Ed. Coimbra, n. 13, p. 9-32, 2010.

OLIVEIRA, José Lamartine Corrêa de; MUNIZ, Francisco José Ferreira. Curso de direito de família. 4. ed. Curitiba: Juruá, 2009.

PAIVA, João Pedro Lamana; PINHEIRO, Daniela Beling. Da necessidade ou não da escritura pública de pacto (ante) nupcial por ocasião da alteração do regime de bens. Disponível em: <http://registrodeimovei s1zona.com.br/?p=218>. Acesso em 19 jan. 2016.

PASSARELLI, Luciano Lopes. Modificação do regime de bens no casamento. Revista de Direito Imobiliário, v. 27, nº 57, p. 84-109, jul.-dez. 2004. 
PENTEADO, Luciano de Camargo. Direito das coisas. 2. ed. São Paulo: Revista dos Tribunais, 2012.

. Efeitos contratuais perante terceiros. São Paulo: Quartier Latin, 2007.

PEREIRA, Caio Mário da Silva. Instituições de direito civil: direito de família. 16. ed. Rio de Janeiro: Forense, 2007. v. 5.

. Instituições de direito civil: direito de família. 11. ed. Rio de Janeiro: Forense, 1997. v. 5.

. Instituições de direito civil: introdução ao direito civil. Teoria geral do direito civil. 22. ed. Rio de Janeiro: Forense, 2007. v. 1.

PEREIRA, Lafayette Rodrigues. Direitos de família. Rio de Janeiro: Typ. da Tribunal Liberal, 1889.

PEREIRA, Rodrigo da Cunha. Dicionário de direito de família e sucessões ilustrado. São Paulo: Saraiva, 2015.

PEREIRA, Sérgio Gischkow. O direito de família e o novo Código Civil: alguns aspectos polêmicos ou inovadores. Revista Brasileira de Direito de Família, Porto Alegre: Síntese, no 18, jun.-jul. 2003.

A alteração do regime de bens: possibilidade de retroagir. Revista Brasileira de Direito de Família, Porto Alegre: Síntese, no 24, abr.-maio 2004.

PONTES DE MIRANDA, Francisco Cavalcanti. Comentários à Constituição de 1946. Rio de Janeiro: Borsoi, 1963. t. 4.

. Tratado de direito de família. 3. ed. São Paulo: Max Limonad, 1947. v. 2.

- Tratado de direito privado: parte especial: direito das coisas: condomínio. Edifício de apartamentos. Compáscuo. Terras devolutas. Terras de sivícolas. 2. ed. Rio de Janeiro: Borsoi, 1958. t. 12.

. Tratado de direito privado: parte especial: direito das obrigações: obrigações e suas espécies de obrigações. 2. ed. Rio de Janeiro: Borsoi, 1958. t. 22.

- Tratado de direito privado: parte especial: dissolução da sociedade conjugal. Eficácia jurídica do casamento. 2. ed. Rio de Janeiro: Borsoi, 1958. t. 8.

. Tratado de direito privado: parte geral: eficácia jurídica. Determinações inexas e anexas. Diretos. Pretensões. Ações. 2. ed. Rio de Janeiro: Borsoi, 1955. t. 5.

RANGEL, Rafael Calmon. Partilha de bens na separação, no divórcio e na dissolução da união estável. São Paulo: Saraiva, 2107. E-book. 
REIS, Clayton. A mudança do regime de bens no casamento em face do novo Código Civil brasileiro. Revista Brasileira de Direito de Família, v. 5, nº 20, p. 5-19, out.-nov. 2003.

RIZZARDO, Arnaldo. Direito de família. 4. ed. Rio de Janeiro: Forense, 2006.

ROCHA, Carmen Lúcia Antunes. O princípio do direito adquirido no direito constitucional. Revista de Informação Legislativa, v. 26, n 103, p. 147-162, jul.-set. 1989.

(Org.). Constituição e segurança jurídica: direito adquirido, ato jurídico perfeito e coisa julgada: estudos em homenagem a José Paulo Sepúlveda Pertence. Belo Horizonte: Fórum, 2004.

RODRIGUES, Silvio. Direito civil: direito de família. 28. ed. São Paulo: Saraiva, 2008. v. 6.

RODRIGUES JUNIOR, Otavio Luiz. Distinção sistemática e autonomia epistemológica do direito civil contemporâneo em face da Constituição e dos direitos fundamentais. Tese (Livre-docência). São Paulo: Universidade de São Paulo, Faculdade de Direito, 2017.

- Suprema Corte britânica valida pacto antenupcial. Disponível em $<$ http://www.conjur.com.br/2012-out-17/direito-comparado-suprema-corte-britanicavalida-pacto-pre-nupcial>. Acesso em: 20 out. 2016.

ROPPO, Vincenzo. Il contratto. Milano: Giufré, 2001.

ROUBIER, Paul. Les conflits de lois dans le temps. Paris: Recueil Sirey, 1929.

RUGGIERO, Roberto de. Instituições de direito civil. São Paulo: Saraiva, 1958. v. 2.

SANTOS, Antônio Jeová. Direito intertemporal e o novo Código Civil: aplicações da Lei 10.406/2002. 2. ed. São Paulo: Revista dos Tribunais, 2004.

SANTOS, Francisco Cláudio de Almeida. O pacto antenupcial e a autonomia privada. In: BASTOS, Eliene Ferreira; SOUSA, Asiel Henrique de (Coord.). Família e jurisdição. Belo Horizonte: Del Rey, 2006. p. 183-209.

SANTORO-PASSARELLI, Francesco. L'autonomia privata nel diritto di famiglia. Saggi di diritto civile. Napoli: Jovene, 1961. v. 1.

SANTOS, Antonio Jeová. Direito intertemporal e o novo Código Civil. 2. ed. São Paulo: Revista dos Tribunais, 2004.

SANTOS, Luiz Felipe Brasil. Autonomia da vontade e os regimes matrimoniais de bens. In: WELTER, Belmiro Pedro; MADALENO, Rolf Hanssen (Coord.). Direitos fundamentais do direito de família. Porto Alegre: Livraria do Advogado, 2004. 
. A mutabilidade dos regimes de bens. Disponível em: $<$ http://www.migalhas.com.br/dePeso/16,MI2295,101048A + mutabilidade+dos + regime s+de+bens $>$. Acesso em: 11 nov. 2015.

SCHREIBER, Anderson. A proibição do comportamento contraditório: tutela de confiança e venire contra factum proprium. 3. ed. Rio de Janeiro: Renovar, 2012.

SERPA LOPES, Miguel Maria de. Comentários à Lei de Introdução ao Código Civil. 2. ed. Rio de Janeiro: Freitas Bastos, 1959. v. 1.

Curso de direito civil. 4. ed. Rio de Janeiro: Biblioteca Jurídica Freitas Barros, 1960. v. 6.

SILVA, Clóvis Veríssimo do Couto e. Direito patrimonial de família no Projeto de Código Civil brasileiro e no direito português. Revista dos Tribunais, São Paulo: Revista dos Tribunais, v. 520, p. 11-37, fev. 1979.

SILVA, José Mônaco da. O casamento, o regime de bens à luz do direito comparado e o novo regime de participação final nos aqüestos. Tese (Doutorado em Direito). São Paulo: Pontifícia Universidade Católica, 2006.

SIMÃO, José Fernando. A Emenda Constitucional n. 66: a revolução do século em matéria de Direito de Família. Revista do advogado, São Paulo, ano 31, n 112, p. 64-78, jul. 2011.

. Tempo e direito civil: prescrição e decadência. Tese (Livre-docência). São Paulo: Universidade de São Paulo, 2011.

. Estatuto da pessoa com deficiência causa perplexidade (Parte 2). Disponível em: $<$ http://www.conjur.com.br/2015-ago-07/jose-simao-estatuto-pessoa-deficiencia-trazmudancas $>$. Acesso em: 20 out. 2016.

. Mudança de regime de bens e pacto antenupcial: um diálogo necessário. Jornal Carta Forense, mar. 2014. Disponível em: <http://www.cartaforense. com.br/conteudo/colunas/mudanca-de-regime-de-bens-e-pacto-antenupcial-umdialogonecessario/13184>. Acesso em: 17 set. 2016.

. Novamente a mudança do regime de bens? Maiores de 70 anos. Disponível em: $<$ http://www.cartaforense.com.br/conteudo/colunas/novamente-a-mudanca-do-regimede-bens-maiores-de-70-anos/11505>. Acesso em: 11 set. 2015.

Retroagir ou não retroagir: eis a questão! Disponível em: $<$ https://www.conjur.com.br/2015-set-27/processo-familiar-retroagir-ou-nao-retroagireis-questao $>$. Acesso em: 20 out. 2016. 
O Código Civil e as decisões dos Tribunais - A mudança de regime de bens. Disponível em: <http://www.cartaforense.com.br/conteudo/colunas/o-codigo-civil-eas-decisoes-dos-tribunais---a-mudanca-de-regime-de-bens/226>. Acesso em: 11 set. 2015.

- Questões controvertidas - a mudança do regime de bens. Disponível em: $<$ http:/www.cartaforense.com.br/conteudo/colunas/questoes-controvertidas---amudanca-do-regime-de-bens-3a-parte/99>. Acesso em: 11 set. 2015.

. A não manutenção do foro privilegiado para mulher casada no novo CPC. Disponível em: $<$ https://www.conjur.com.br/2015-mai-03/processo-familiar-naomanutencao-foro-privilegiado-mulher-casada-cpc>. Acesso em: 04 fev. 2018.

. Leis, História e histórias - Regime da separação obrigatória - Lei 12.344/2010. Disponível em: < http://www.cartaforense.com.br/conteudo/colunas/leis-historia-ehistorias---regime-da-separacao-obrigatoria---lei-123442010/6434>. Acesso em: 13 abr. 2016.

. Mutabilidade do regime da separação obrigatória - Decisão surpreendente! Disponível em: <http:/www.cartaforense.com.br/conteudo/colunas/mutabilidade-doregime-da-separacao-obrigatoria---decisao-surpreendente/2379>. Acesso em: 13 abr. 2017.

. A teoria dualista do vínculo obrigacional e sua aplicação ao direito civil brasileiro. In: PAULA, Fernanda Pessoa Chuahy de; MENEZES, Iure Pedroza; CAMPELLO, Nalva Cristina Barbosa. Direito das obrigações: reflexões no direito material e processual. São Paulo: Método, 2011. p. 239-254.

SIMÕES, Thiago Felipe Vargas. Regimes de bens no casamento e na união familiar estável. Porto Alegre: Livraria do Advogado, 2015.

STANZIONE, Gabriella Autorino. Diritto di famiglia. Torino: G. Giappichelli Editore, 2003.

TARTUCE, Flávio. Direito civil. Rio de Janeiro: Forense, 2015.

TEPEDINO, Gustavo. As relações de consumo e a nova teoria contratual. Temas de direito civil. 3. ed. Rio de Janeiro: Renovar, 2004.

. Controvérsias sobre regime de bens no novo Código Civil. Revista Brasileira de Direito das Famílias e Sucessões, Belo Horizonte, ano IX, nº 2, p. 5-21, fev.-mar. 2008.

TOLOMEI, Carlos Young. A proteção do direito adquirido sob o prisma civilconstitucional: uma perspectiva sistemático-axiológica. Rio de Janeiro: Renovar, 2005. 
TRABUCCHI, Alberto. Istituzioni di diritto civile. 44. ed. Padova: CEDAM, 2009.

TUCCI, Cibele Pinheiro Marçal. Contratualização da família. Revista do Advogado, São Paulo, ano32, n.116, p. 60-69, jul. 2012.

VELOSO, Zeno. Regimes matrimoniais de bens. In: PEREIRA, Rodrigo da Cunha (Coord.). Direito de família contemporâneo. Belo Horizonte: Del Rey, 1997.

VENOSA, Silvio de Salvo. Direito civil: direito de família. 4. ed. São Paulo: Atlas, 2004. v. 6.

. Direito civil: parte geral. 4. ed. São Paulo: Atlas, 2004. v. 1.

VIANNA, Tauanna Gonçalves. Pacto antenupcial: delimitações de seu objeto. Dissertação (Mestrado em Direito). São Paulo: Universidade de São Paulo, 2016.

VILLELA, João Baptista. Regime de bens no casamento: revogabilidade e segurança de terceiros. Estudos de Direito brasileiro-alemão. Porto Alegre: Gráfica UFRGS, 1985.

WALD, Arnoldo. O novo direito de família. 13. ed. São Paulo: Saraiva, 2000.

WAMBIER, Teresa Arruda Alvim; DIDIER JR., Fredie; TALAMINI, Eduardo; DANTAS, Bruno (Coord.) Breves comentários ao novo Código de Processo Civil. São Paulo: Revista dos Tribunais, 2015.

WESENDONCK, Tula. Direito patrimonial de família: disciplina geral do regime de bens no Código Civil. São Paulo: Elsevier, 2011.

XAVIER, José Tadeu Neves. Questões relevantes sobre a mutabilidade do regime de casamento. Revista de Direito Privado, São Paulo: Revista dos Tribunais on-line, v. 52, p. 193-228, out.-dez. 2012.

ZANNONI, Eduardo A. Liquidación y calificación de bienes de la sociedade conyugal. Buenos Aires: Editorial Astrea de Alfredo y Ricardo Depalma, 1976. 